\title{
Flow Simulation and Model Analysis of Efficiency and Pressure Ratio Behaviours in GT4086 Turbocharger Compressor
}

\author{
Mohammad OMIDI*, Shu-jie LIU*, Soheil MOHTARAM**, Hui-tian LU***, \\ Hong-chao ZHANG***** \\ *School of Mechanical Engineering, Dalian University of Technology, Dalian, Liaoning, 116024, P.R. China \\ **Institute of Soft Matter Mechanics, College of Mechanics and Materials, Hohai University, Nanjing 210098, China \\ ***Department of Construction \& Operations Management, South Dakota State University, Brookings, SD 57007, USA \\ ****Department of Industrial Engineering, Texas Tech University, Lubbock, TX 79409, USA \\ Corresponding Author: E-mail address: liushujie@dlut.edu.cn (Liu. Shu-jie)
}

cross $^{\text {ref }}$ http://dx.doi.org/10.5755/j01.mech.26.4.23867

\section{Nomenclature}

$I G V$ - Inlet Guide Vane; CFD - Computational Fluid Dynamics; $\psi_{T}-$ Theoretic Head Coefficient; rpm - Round Per Minute; $C C M$ - Coordinate Measuring Machine; $B E P$-Best Efficiency Point; $\phi$ - Flow Coefficient; $\eta$ - Isentropic Efficiency; $P_{r}-$ Pressure Rati; $\gamma$ - Friction Coefficient; $T$-Temperature, $C C D$ - Centrifugal Compressors Design; CT.Scan - Computed tomography Scan; $P C A$ - Principal Component Analysis

\section{Introduction}

Turbomachines play a crucial role in the industry of fluids process. Compressors are used as a significant turbomachine in aerospace, automobile, power plants, and oil industries [1]. The main advantages of centrifugal compressors include a wide performance range, high efficiency, reliability, and resistance against external objects. Recently, an increment in using and understanding of the modeling and optimization of turbomachines by artisans, governments, and academics has been observed.

Studies that conducted to model and optimize compressors can be categorized into four main groups including [2]:

1. Design of centrifugal compressor impeller.

2. Impeller optimization.

3. 3D simulation of compressors.

4. Experimental studies on flow inside the compressor. $\mathrm{Xu}$ and Muller designed a new volute for a centrifugal compressor [3] using a structured mesh for the impeller and an unstructured mesh for the volute. Given the high simulation costs, they had no choice but to use a zero-equation model for turbulence. They imposed the total pressure boundary condition at the inlet and the static pressure at the outlet. Xu and Amano simulated an entire compressor [4] using a total of about 8 million elements in a k-e model. This large number of elements improved the accuracy at the expense of simulation cost. Raja Kumar simulated a centrifugal compressor in different operating conditions [5] using a $\mathrm{k}$-e model and considering the static pressure condition for the outlet and the total pressure condition for the inlet. Krain $[6,29]$ showed that the shroud and suction side is apparently not a general pattern and that this jet and wake strongly depends on the impeller shape and diffuser design. The presence of a secondary flow [7] rather than following the im- peller's flow by flow is a common point in all the experimental studies. The point of instability initiation is another point in these studies. Instability was shown to begin at the starting point of the curvature in the hub where the channel starts to change direction. This is a major point in the design of splitter blades, as they start at this place, suggesting that the flow is not coincident with the inlet angle of splitter blades. Cumpsty and Senoo found different flow distributions to be normal in the two channels separated by splitter blades $[8,9]$. Fig. 1 shows Secondary flow streamlines in the impeller developed by Cumpsty. Numerical studies, including the one by Keneko [10], also showed and clarified this distribution of flow for the design and optimization of centrifugal compressors [11].

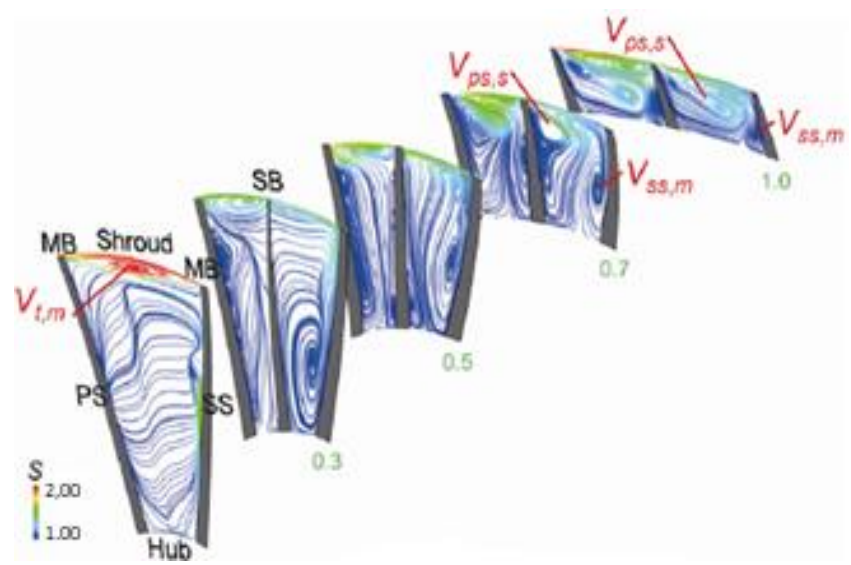

Fig. 1 Secondary flow streamlines in the impeller [8]

Impeller optimization is an interesting research area. A novel study by Swine changed the impeller design $[12,13]$ using axial, radial and stream-wise directions of correction. This so-called trimming method begins with a scratch design of the impeller and continues to make the design more delicate, which affects the impeller boundaries in different directions. Kim also optimized a compressor and achieved a $0.6 \%$ improvement in pressure ratio [14] and $1.4 \%$ in efficiency by redefining the curve at the hub and shroud through changing the control points in the Bezier polynomial [15]. Changing the impeller's shape and number is another general method for their optimization. In this regard, Layth investigated the effect of inserting two splitter blades between the main blades instead of using conventional method [16]. They could improve the mass flow rate 
and even efficiency and pressure ratio. Ibaraki also conducted an experimental study on this subject [17]. Sugimura et al. developed an optimization method by changing blades shape [18] while investigating the instability margin of the compressor. They found the inlet angle of the impeller to significantly affect the compressor efficiency. In addition, the outer radius and the outlet width were found to contribute to instability. They didn't change the shape of blades. Neverov et al. [19] used the NUMECA Fine/Turbo package with Spalart - Allmaras and Shear Stress Transport turbulence models, and investigated two radial impellers with a high-pressure at $\psi_{T}=0.71$ and a low-pressure at $\psi_{T}=0.43$. Shahram Derakhshan and Derakhshan investigated the slurry flow in centrifugal pumps to obtain an efficient optimization procedure. KM Guleren optimized a centrifugal pump using genetic algorithms [20] coupled with CFD considering flow physics for different impeller-diffuser configurations modelled with the maximum pressure increase and minimum relative flow angle as two objective functions. The results showed a significant increase in the pressure at the design flow rate $(15.5 \%)$, and a decrease at larger flow rates in the first optimization. The second optimization was performed after enhancing the head for the entire mass flow rates with an average increase of $25.74 \%$ [21]. Kaibin Wang et al. presented an optimization strategy for the aerodynamic performance of an impeller at the design point with an efficiency constraint at the stall point [22]. S.A Mousavi and M. Mojaddam optimized different models of impeller designs by using various algorithms and computational fluid dynamics methods, applied on the GT4082. The results show a significant increase in the pressure ratio, efficiency, and extension of the surge point [23-28].

This study used a middle-sized turbocharger compressor GT-4082 made by Garret Company. This compressor is ideal for experimental tests given its no operational requirements for a huge gearbox. The purpose is to model and simulate the function of a centrifugal compressor and evaluates the effects of losses in the impeller, volute, and diffuser. It is also examined the mass parameter effect on the efficiency drop at different speeds. The total and static pressure drops are also examined in the volute and diffuser.

\section{Modeling assumption and initial description:}

According to Fig. 2, splitters make the structure too complex although GT 4082 has no inlet guide vane (IGV) at the inlet. Fig. 3 shows the characteristic curve and Table 1 the characteristics of the compressor.

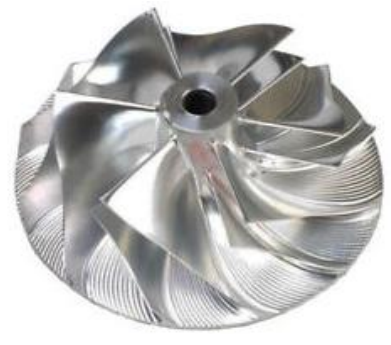

Fig. 2 GT-4082 compressor impeller

Given the holes inside the compressor, coordinate measuring machine (CMM), 3D scan and laser photography are not appropriate for 3D modeling, and CT scan can therefore be used to obtain a $3 \mathrm{D}$ model of the compressor. The accuracy of CT-scan is approximately $0.5 \mathrm{~mm}$. Fig. 4 shows the steps of developing a 3D model of the compressor impeller. The output of the CMM software and CT-scan are considered as the input of the Ansys blade production environment and the impeller and diffuser are modeled in it.

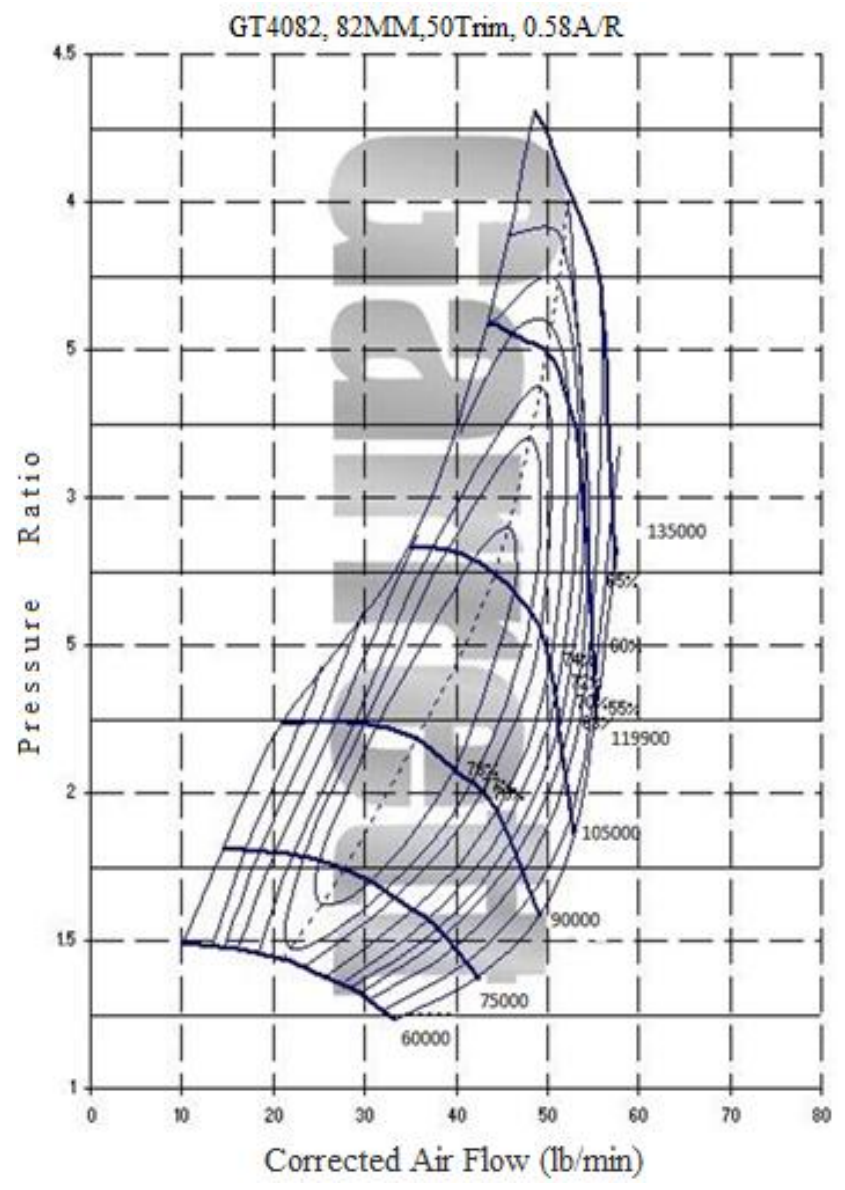

Fig. 3 The characteristic curve of GT4082

Table 1

Characteristics of GT-4082

\begin{tabular}{|c|c|}
\hline Parameter & Value \\
\hline Nominal pressure ratio & 2.25 \\
\hline Nominal mass flow, kg/s & 0.28 \\
\hline Nominal rpm & 92000 \\
\hline Inlet temperature, $\mathrm{K}$ & 288 \\
\hline Inlet pressure, KPA & 101 \\
\hline Nominal efficiency (\%) & 78 \\
\hline Ratio of relative velocities & 0.63 \\
\hline Inlet diameter at hub, cm & 22 \\
\hline Inlet diameter at shroud, cm & 54 \\
\hline Number of full and splitter blades & $6+6$ \\
\hline Back swept angle, degree & 38 \\
\hline Lean angle, degree & 55 \\
\hline Ratio of axial length to diameter & 0.33 \\
\hline
\end{tabular}

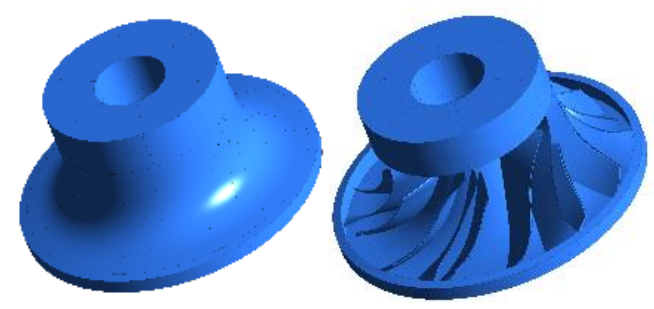

Fig. 4 The steps of geometry developing, primary step (left) secondary step (right) 
The importance of model accuracy lies in the fact that errors in the 3D model can cause major differences in final simulation results. Figs. 5, 6 show the 3D model of the impeller. Fig.5 shows the impeller meshing, and Fig.6 shows the velocity streamline in impeller.

Simulation of the flow field throughout the entire machine allows an analysis of the compressor. The software applied to this simulation was CFX. Because flow modelling is a crucial element of 3D simulation, we used CFX, as it is fundamentally designed for turbomachines and is therefore more apt to connect rotary parts and stationary parts of compressors than other fluid-modelling modules, although CFX is an ANSYS module for fluid simulation.

There is a BEP for the base compressor design, and optimization is usually conducted at this stage; however, the current research took into account optimization throughout the entire operating spectrum of the compressor at the nominal speed, [30-31] have shown the code validation for turbomachines flows.

Scrutinizing the details of the flow is the main purpose of 3D modeling. Results using this method are accurate and faithful to actual circumstances, as simplifications are rare. Elements that would be absent from 1D and 2D models, such as turbulence, backflow, and vortexes, are present in the 3D models. The geometry of the flow domain is one of the main requirements in $3 \mathrm{D}$ modeling.

One of the most crucial factors to ensure an effective and accurate modelling of flow is having an appropriate grid. Certain basic errors of modelling, as well as computational costs, may be determined by grids of domain. The contour of grids is particularly important at regions near the walls. Grid generation is made all the more crucial due to the sophisticated geometry of turbomachines. Grid generation for rotary components will be done by structured methods, and with the exception of regions such as the volute, where an unstructured, asymmetrical grid is appropriate, this choice renders the process more efficient.

The following aspects are especially important and require attention within the simulation:

The Transient Rotor-Stator and Frozen-Rotor Simulation method will be applied for the connection of various parts. This method, in addition to functioning not only for averaged flow properties, also saves details of flow. For numerous parts of the machine, a steady state solution is attained via application of the frozen-rotor simulation. To be precise, the condition remains steady and the equipment's geometry does not change.

Flow is steady.

The turbulence method is SST (Menter's Shear Stress Transport). This model primarily attains the highest degree of accuracy in predicting the onset and division of mass flow under adverse pressure gradients. The model exhibits high performance in observing both near-wall flows and secondary flows. The computational results yielded by this model show significant improvement in flow separation. Several studies have validated the advanced performance of this model. Additionally, SST is recommended for simulating the boundary layer with high accuracy [32-33].

The standard $k-\varepsilon$ turbulence model was employed to model the effects of turbulence. A wall function is used to resolve the wall flows and also to improve the simulation time. It has merits of $k-\varepsilon$ and $k-\omega$ both near to and far from the walls.
Mass flow is the boundary condition at the outlet, while temperature and static pressure of the air constitute the boundary conditions at the inlet. Several different forms of boundary conditions may be utilized at the inlet boundary. For example, one may specify total pressure or the mass flow rate (velocity). In most computational cases, the mass flow rate is specified over the whole inlet face of the impeller. The measured state pressure is employed as an average value over the volute's outlet area, yielding an approximate mass flow of $0.287 \mathrm{~kg} / \mathrm{s}$. Total pressure is used at the inlet so that the computations may analyze the parameter of performance with the highest degree of accuracy. The diffuser and volute both remain stationary while the impeller turns with a rotational speed of $92,000 \mathrm{rev} / \mathrm{min}$ [20].

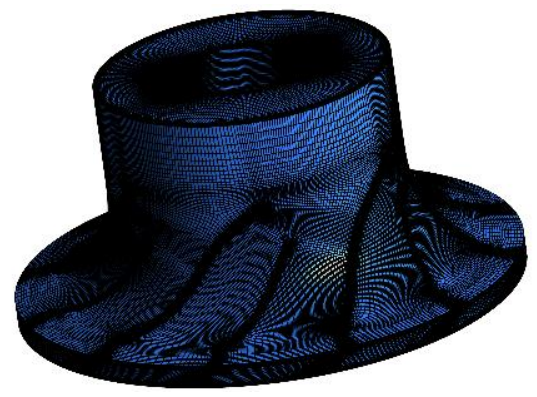

Fig. 5 The impeller geometry

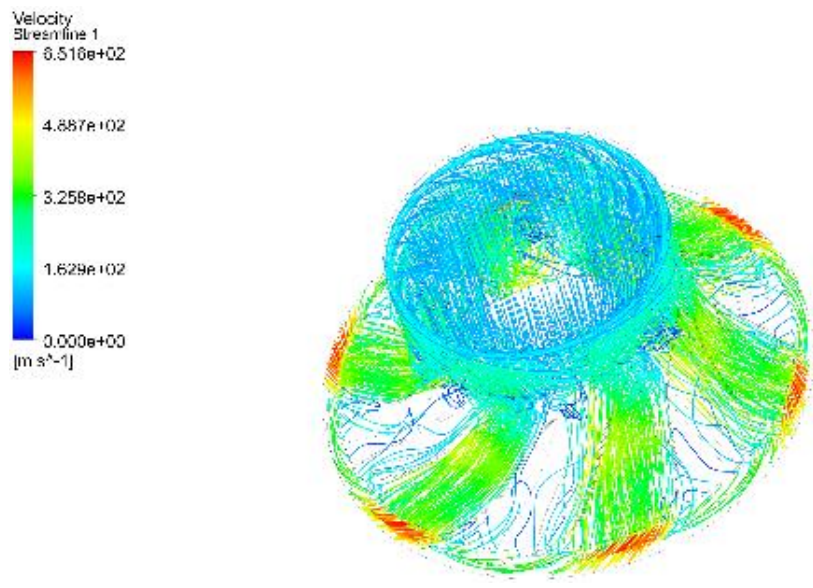

Fig. 6 The method of parallel surface in the impeller

The results of nominal specifications of the compressor were inserted into Vista CCD, and its performance curves are monitored (Fig. 7). This software is developed by PCA Company as a reliable program for performance prediction and design of compressors. Figs. 8 and 9 show the obtained results are modified by comparing them with the nominal curves of the compressor and certain geometrical tolerances and errors.

\section{Validation}

According to shown figures below (figs 10 and 11), the results of a reliable experimental study with the mostdetailed input parameters to simulations were used to investigate the accuracy and validity of the proposed simulation method by simulating and comparing these results with those of the simulation method. [24] The equation below is utilized to measure performance by way of assessing pressure ratio and isentropic efficiency from a compressor inlet to a diffuser outlet: 


$$
\begin{aligned}
& P_{r}=P_{2 t} / P_{1 t}, \\
& \eta_{t t}=\frac{T_{01}\left(P R^{\gamma-1 / \gamma}-1\right)}{\left(\bar{T}_{02}-T_{01}\right)} .
\end{aligned}
$$

The results used were associated with the original geometry at a 70,000 rpm. The results in the current study were therefore found to correctly simulate the compressor behavior with a maximum $4.2 \%$ error [6].

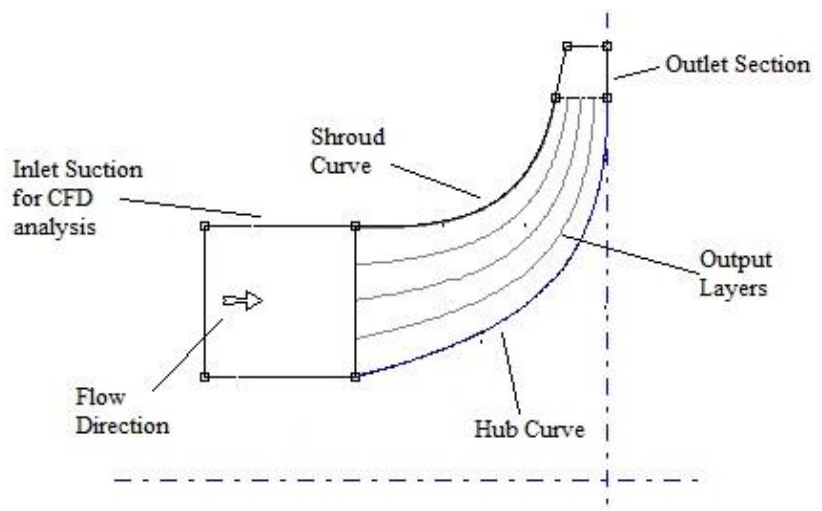

a

b

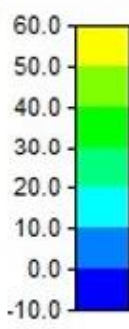

c

Fig. 7 Meridional contour view; a) splitter; b and c) blade

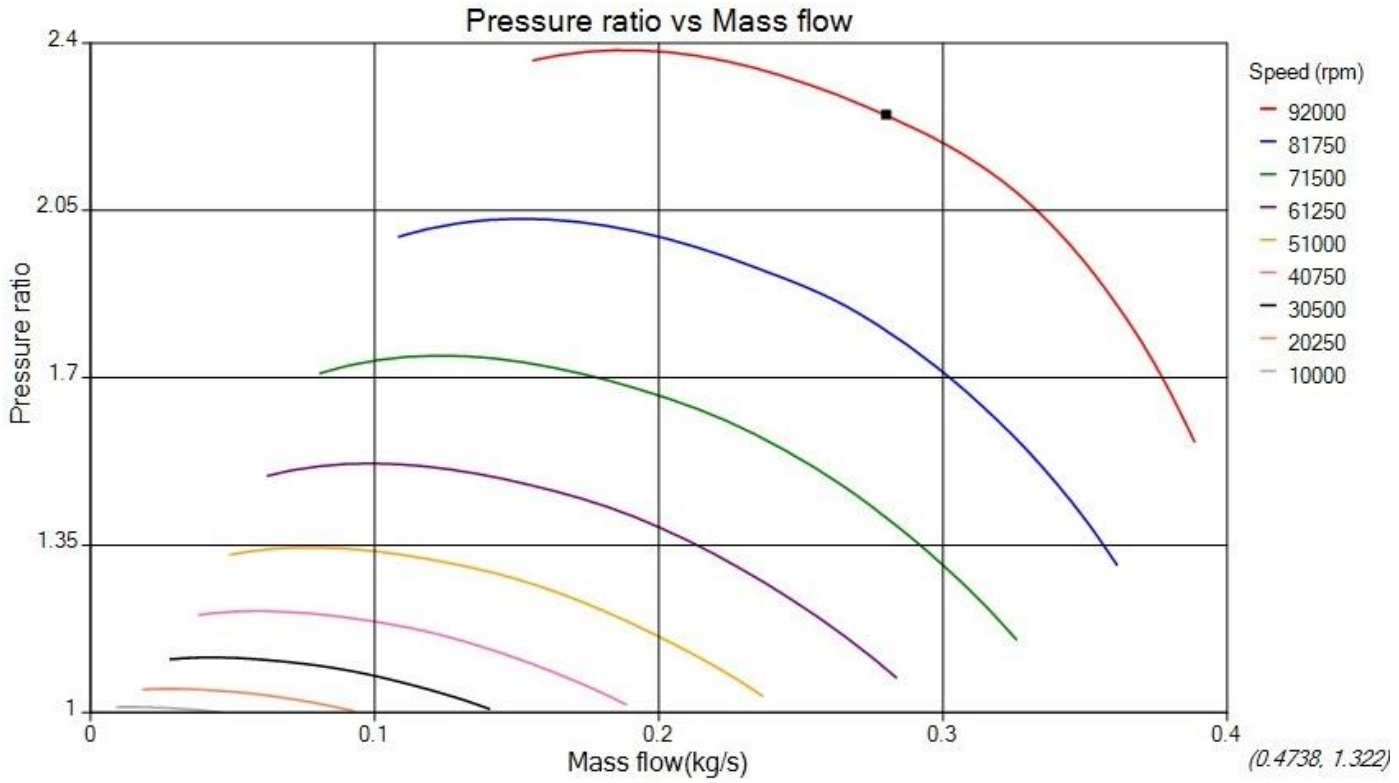

Fig. 8 Pressure ratio versus mass flow

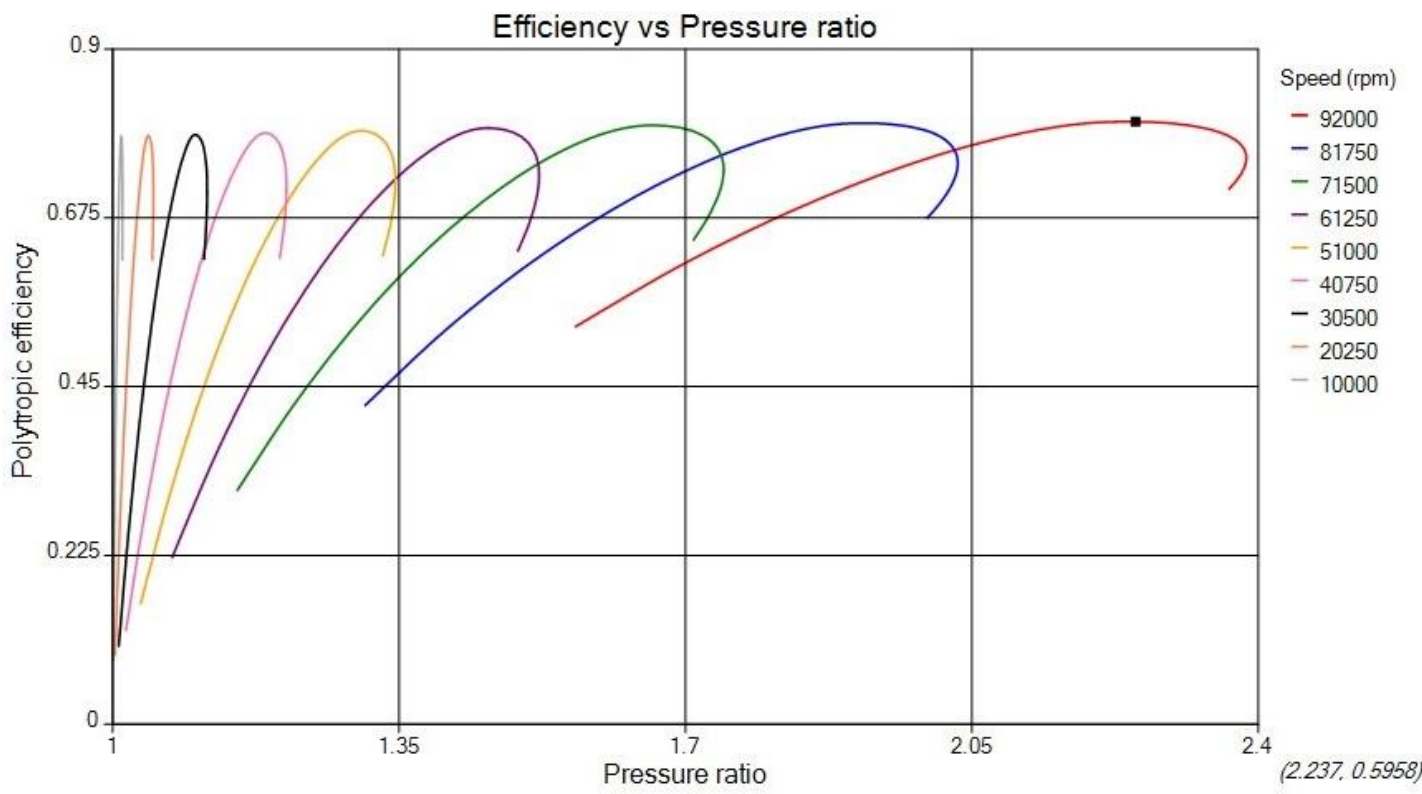

Fig. 9 Efficiency versus pressure ratio 


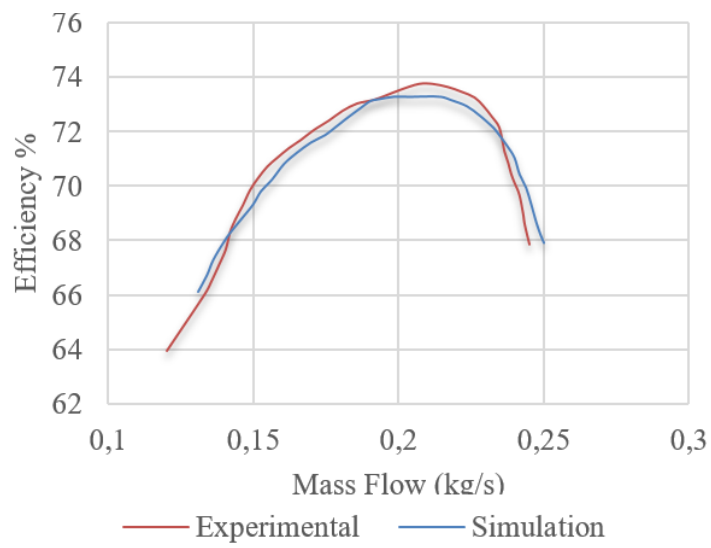

Fig. 10 Evaluating the efficiency accuracy in simulations using a reliable experimental study

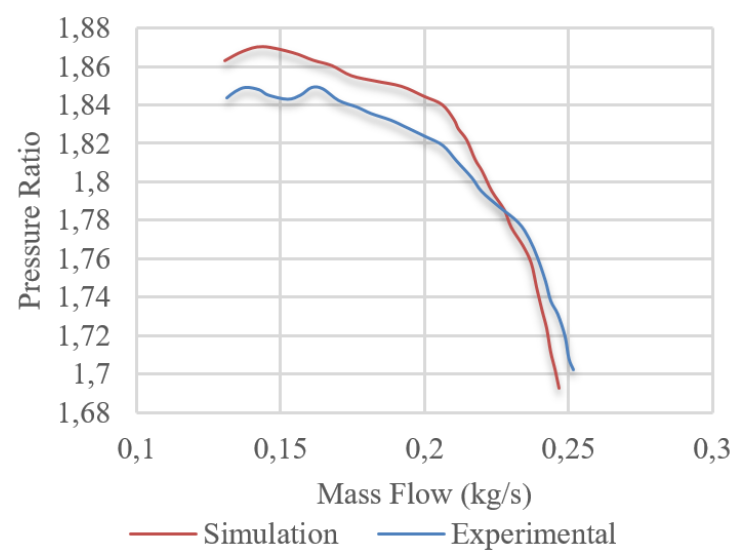

Fig. 11 Evaluating the pressure ratio accuracy in simulations using a reliable experimental study

\section{Results and discussion}

Losses in different components of the compressor should be investigated to determine improvement requirements in different parts. As the first step for calculating performance parameters for every part of the compressor, parameters such as pressure and temperature can be calculated in different sections. The static and total pressure ratio and the separate efficiency of the parts can also be analyzed. These parameters were calculated using the average mass flow.

Fig. 12 shows the efficiency drop in the diffuser versus the compressor speed, suggesting the highest efficiency drop at 90,000 rpm, while this drop was lower at lower speeds.

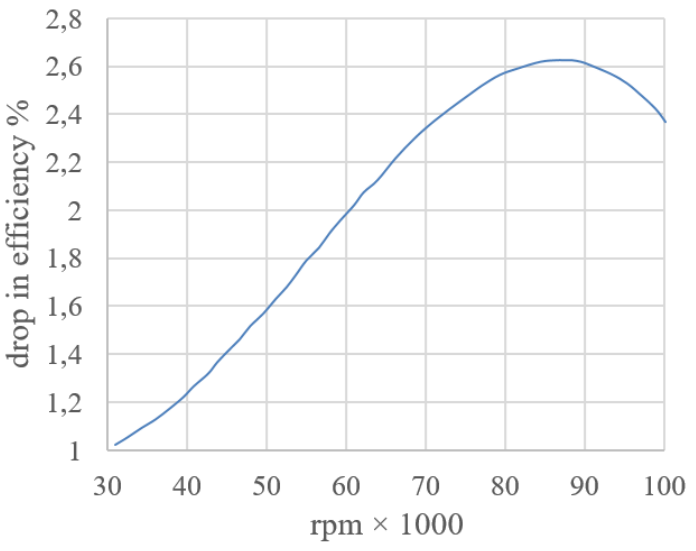

Fig. 12 Diffuser's losses at the BEP mass flow rate
Fig. 13 shows the efficiency drop associated with the impeller versus compressor speed as a significantly-effective factor.

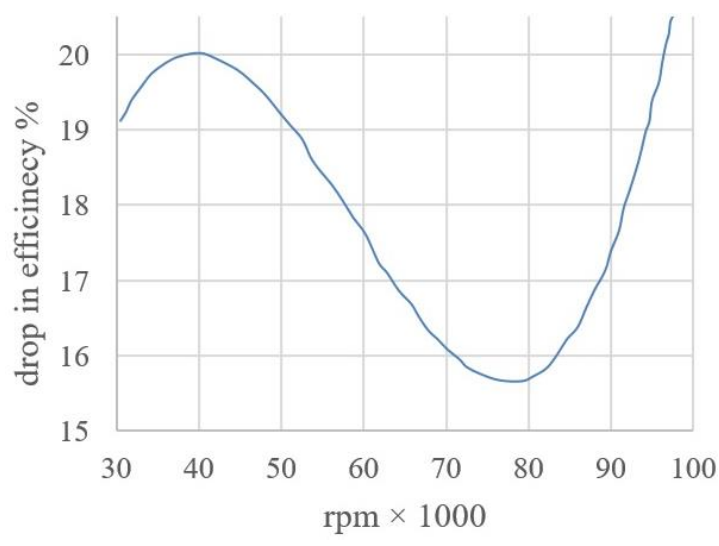

Fig. 13 Impeller's losses at the BEP mass flow rate

Fig. 14 shows the efficiency drop in the volute, suggesting a maximum drop of $2.7 \%$ at $50,000 \mathrm{rpm}$.

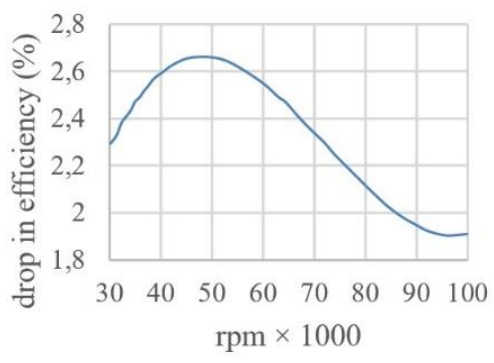

Fig. 14 Volute's losses in the BEP mass flow rate

The efficiency drop with mass parameters was then investigated by simulating the compressor at different speeds in the entire range of mass flows. Figs.15,16, and 17 show the efficiency drop with mass parameter, suggesting a more linear trend with an optimum point in which the compressor performance can be maximized.

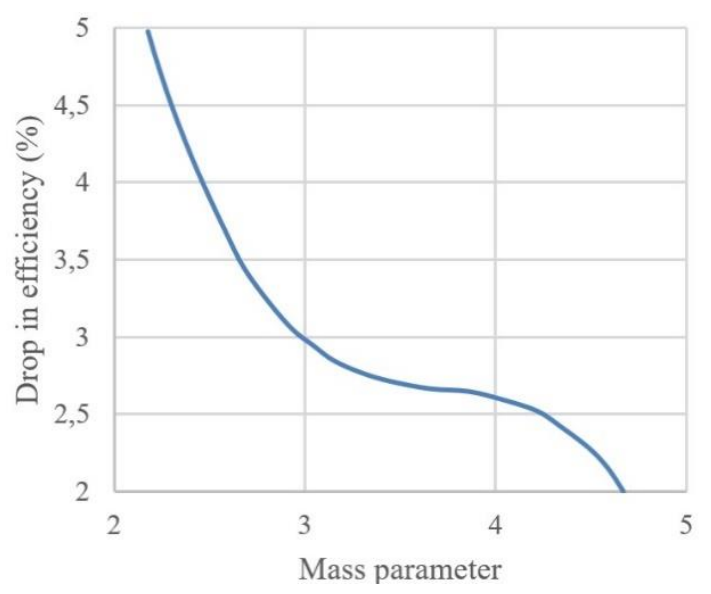

Fig. 15 Diffuser's losses at a 90 k rpm

Pressure ratio is an important parameter of compressors. Given the mechanism of impellers, losses in pressure ratio are undefinable. The impeller injects kinetic energy into the flow, and the part where this energy is wasted cannot be specified. Fig. 18 and Fig. 19 show the total pressure drop in the diffuser and volute, and suggest a minimum in both curves. 


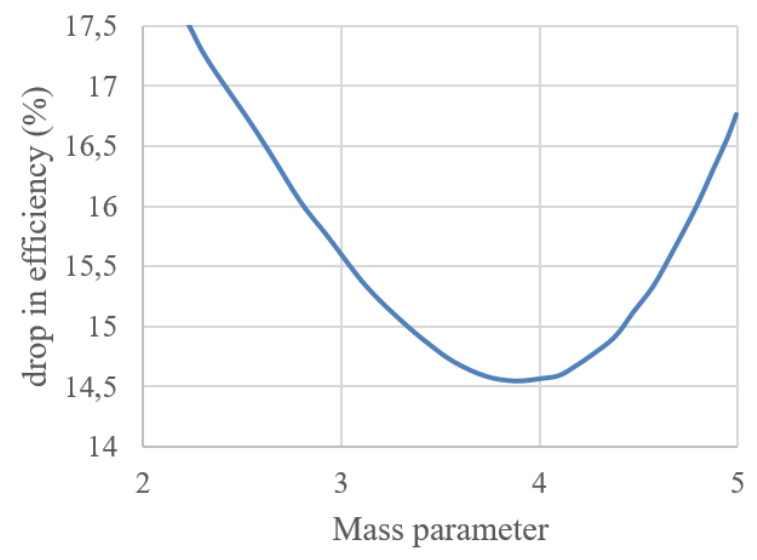

Fig. 16 Impeller's losses at a 90k rpm

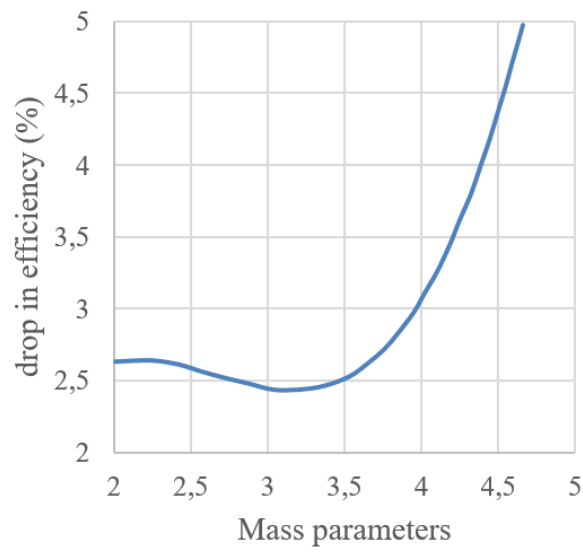

Fig. 17 Volute's losses at a 90k rpm

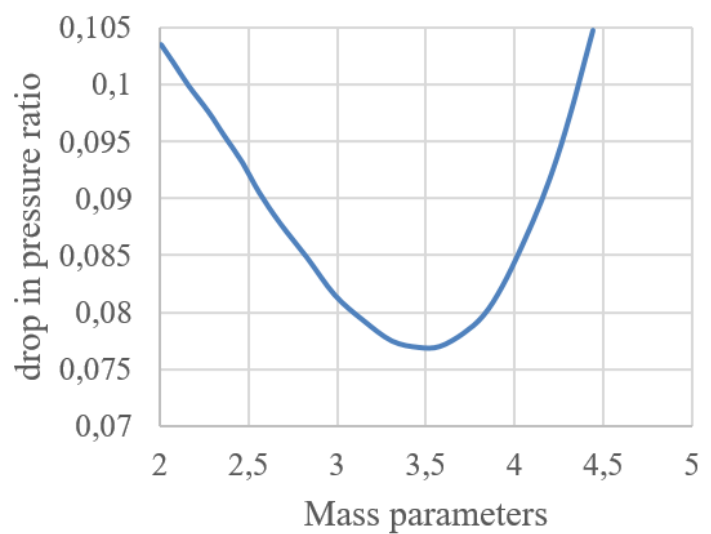

Fig. 18 The total pressure drop associated with the diffuser

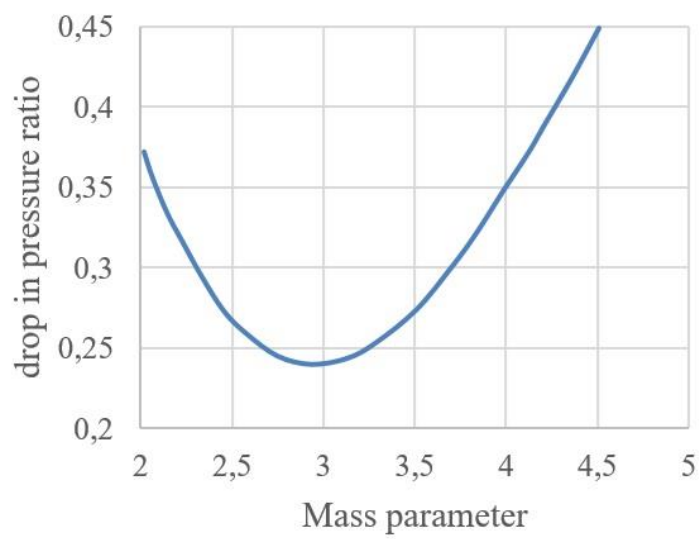

Fig. 19 The total pressure drops associated with the volute
Figs. 20 and 21 show the static pressure drop associated with the diffuser and volute.

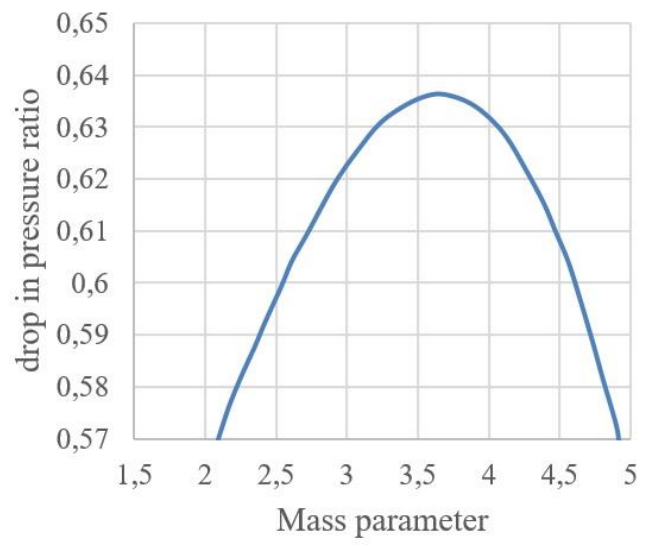

Fig. 20 The static pressure drop for the diffuser

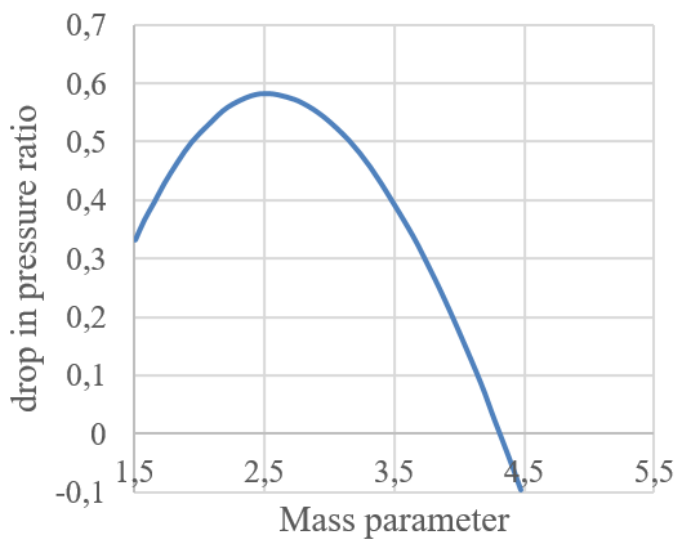

Fig. 21 The static pressure drop for the volute

Static pressure represents the pressure energy that can be used for a device, and the total energy is the entire flow energy convertible to pressure. The total pressure drop was found to be much higher in the volute than in the diffuser, whereas the static pressure drop was nearly the same.

\section{Conclusion}

The present article performed a 3D simulation of a GT 4082 compressor, and modelled and investigated the flow patterns of the impeller, volute and diffuser. The results were therefore found to correctly simulate the compressor behavior with a maximum $4.2 \%$ error.

The efficiency drops in these parts modeled at different mass parameters and speeds were shown to be maximized in the volute and diffuser at a specific speed. The total and static pressure drops were also examined in the volute and diffuser. Efficiency drop associated with the impeller versus compressor speed as a significantly-effective factor, Figs. $17-19$. efficiency drop in the volute, suggesting a maximum drop of $2.7 \%$ at $50000 \mathrm{rpm}$. A global minimum was observed in the total pressure drop and a global maximum in the static pressure drop versus mass parameter Figs. $20-23$.

\section{Acknowledgements}

This research investigation was supported by the Science and Technology Major Project of Liaoning Province (2019JH1/10100019). 


\section{References}

1. Müller, L. 2019. Adjoint-Based Optimization of Turbomachinery with Applications to Axial and Radial Turbines $266 \mathrm{p}$. https://doi.org/10.35294/phdt201903.

2. Mischo, B.; Jenny, P.; Bidaut Y. 2019. Experimental investigation for enhanced control of rotating unsteady flow instabilities in an unshrouded centrifugal compressor impeller, Proceeding article Turbomachinery 2B: GT2019-90914, V02BT44A015. https://doi.org/10.1115/gt2019-90914.

3. Xu, C.; Müller, M. 2005. Development and design of a centrifugal compressor volute, International Journal of Rotating Machinery 2005: 190-196. https://doi.org/10.1155/ijrm.2005.190.

4. Xu, C.; Amano R. S. 2012. Meridional considerations of the centrifugal compressor development, International Journal of Rotating Machinery 2012: 1-11. https://doi.org/10.1155/2012/518381.

5. Govardhan, D. R. R. M.; Ramamurthy, S. 2012. CFD analysis of flow through mixed flow compressor under various operating conditions, Advances in Aerospace Technology 1: 283-292. https://doi.org/10.1115/imece2012-85695.

6. Krain, H. 1988. Swirling impeller flow, Journal of Turbomachinery 10: 122-128. https://doi.org/10.1115/1.3262157.

7. Nikbakht, M. A.; Mohtaram, S.; Moghadas, M. H. 2018. An investigation on the flow behavior in the airfoil of a flapping wing, International Journal of Engineering Works 5: 138-146. https://doi.org/10.5281/zenodo.1412800.

8. Cumpsty, N. A. 1989. Compressor Aerodynamics. Longman Scientific \& Technical 659 p. https://doi.org/10.1017/s002211209124255x.

9. Senoo, Y.; Hayami, H.; Kinoshita, Y.; Yamasaki, H. 1979. Experimental study on flow in a supersonic centrifugal impeller, Journal of Engineering for Power 101: 32-39. https://doi.org/10.1115/1.3446453.

10. Kaneko, M.; Tsujita, H. 2015. Numerical investigation of influence of tip leakage flow on secondary flow in transonic centrifugal compressor at design condition, Journal of Thermal Science 24: 117-122. https://doi.org/10.1007/s11630-015-0763-5.

11.Swain, D.; Engeda, A. 2014. Performance impact of impeller blade trimming on centrifugal compressors, Proceeding Institution of Mechanical Engineering Part A Journal of Power and Energy 228 878-888. https://doi.org/10.1177/0957650914549788.

12. Swain, D.; Engeda, A. Effect of impeller blade trimming on the performance of a 5.5: 1 pressure ratio centrifugal compressor, Proceeding Institution of Mechanical Engineering Part A, Journal of Power and Energy 228: 602-613. https://doi.org/10.1115/gtindia2012-9525.

13. Swain, D. 2014. Impact of Impeller Blade Trimming on the Performance of Centrifugal Compressors. Michigan State University. $100 \mathrm{p}$.

https://d.lib.msu.edu/etd/3132/datastream/OBJ/downloa d/Impact_of_impeller_blade_trimming_on_the_performance_of_centrifugal_compressors.pdf.
14. Mohtaram, S.; Lin, J.; Chen, W.; Nikbakht, M. A. 2017. Evaluating the effect of ammonia-water dilution pressure and its density on thermodynamic performance of combined cycles by the energy-exergy analysis approach, Mechanika 23: 209-219.

https://doi.org/10.5755/j01.mech.23.2.18110.

15. Kim, J. H.; Choi, J. H.; Husain, A.; Kim, K. Y. 2010 Multi-objective optimization of a centrifugal, Proceeding Institution of Mechanical Engineering Part A, Journal of Power and Energy 224: 711-721. https://doi.org/10.1243/09576509jpe884.

16. Jawad, L. H.; Abdullah, S.; Zulkifli, R.; Mahmood, W. 2012. Numerical simulation of flow inside a modified turbocharger centrifugal compressor, Asian Journal of Applied Sciences 5: 563-572.

https://doi.org/10.3923/ajaps.2012.563.572.

17. Ibaraki, S.; Matsuo, T.; Kuma, H.; Sumida, K.; Suita, T. 2009. Aerodynamics of a transonic centrifugal compressor impeller, Proceeding article Turbomachinery: 473-480. https://doi.org/10.1115/gt2002-30374.

18. Sugimura, K.; Obayashi, S.; Jeong, S. 2010. Multi-objective optimization and design rule mining for an aerodynamically efficient and stable centrifugal impeller with a vaned diffuser, Engineering Optimization $42: 271-293$.

https://doi.org/10.1080/03052150903171084.

19. Neverov, V. V.; Kozhukhov, Y. V.; Yablokov, A. M.; Lebedev, A. A. 2017. Optimization of a centrifugal compressor impeller using CFD: the choice of simulation model parameters, IOP Conference Series, Materials Science and Engineering 232: 012037. https://doi.org/10.1088/1757-899x/232/1/012037.

20. Omidi, M.; Liu, S-J.; Mohtaram, S.; Lu, H-T.; Zhang, H-C. 2019. Improving centrifugal compressor performance by optimizing the design of impellers using genetic algorithm and computational fluid dynamics methods, Sustainability 11: 5409.

https://doi.org/10.3390/su11195409.

21. Guleren, K. M. 2018. Automatic optimization of a centrifugal pump based on impeller--diffuser interaction, Proceeding Institution of Mechanical Engineering Part A, Journal of Power and Energy 232: 1004-1018. https://doi.org/10.1177/0957650918766688.

22. Wang, K.; Ai, X.; Zhang, R.; Li, J. 2018. Optimization of a centrifugal impeller with the constraint on efficiency at the stall point, Open Journal of Fluid Dynamics 8: 1529. https://doi.org/10.4236/ojfd.2018.81002.

23. Moussavi, S. A.; Benisi, A. H.; Durali, M. 2017. Effect of splitter leading edge location on performance of an automotive turbocharger compressor, Energy 123: 511520 . https://doi.org/10.1016/j.energy.2017.02.011.

24. Mojaddam, M.; Moussavi, Torshizi, S. A. 2017. Design and optimization of meridional profiles for the impeller of centrifugal compressors, Journal of Mechanical Science and Technology 31: 4853-4861. https://doi.org/10.1007/s12206-017-0933-3.

25. Mojaddam, M.; Hajilouy-Benisi, A. 2016. Experimental and numerical flow field investigation through two types of radial flow compressor volutes, Experimental Thermal and Fluid Science 78: 137-146. https://doi.org/10.1016/j.expthermflusci.2016.05.016. 
26. Moussavi, Torshizi, S. A.; Benisi, A. H.; Durali, M. 2017. Multilevel optimization of the splitter blade profile in the impeller of a centrifugal compressor, Scientia Iranica 24: 707. https://doi.org/10.24200/sci.2017.4055.

27. Moussavi, Torshizi, S. A.; Hajilouy, Benisi, A.; Durali, M. 2016. Numerical optimization and manufacturing of the impeller of a centrifugal compressor by variation of splitter blades, Proceeding article Turbomachinery 8: GT2016-57105, V008T23A023.

https://doi.org/10.1115/gt2016-57105

28. Moussavi, Torshizi, S. A. 2019. Improving the performance of centrifugal compressors by flow recirculation, Journal of Applied Fluid Mechanics 12: 1791-1799. https://doi.org/10.29252/jafm.12.06.30046.

29. Eisenlohr, G.; Dalbert, P.; Krain, H.; Pröll, H.; Richter, F. A.; Rohne, K. H. 1998. Analysis of the transonic flow at the inlet of a high-pressure ratio centrifugal impeller, Proceeding article 1: Turbomachinery. https://doi.org/10.1115/98-gt-024.

30. Sekavčnik, M.; Tuma, M.; Florjančič, D. 1998. Characteristics of one stage radial centrifugal turbine, Proceeding article 1: Turbomachinery. https://doi.org/10.1115/98-gt-494.

31. Kang, Y. S.; Yoo, J. C.; Kang, S. H. 2004. Numerical study of roughness effects on a turbine stage performance, Proceeding article 1: Turbomachinery 5: Turbo Expo part A and B 1267-1274. https://doi.org/10.1115/gt2004-53750.

32. Menter, F. R. 1994. Two-equation eddy-viscosity turbulence models for engineering applications, AIAA Journal 32: 1598-1605.

https://doi.org/10.2514/3.12149.
M. Omidi, Shu-jie Liu, S. Mohtaram, Hui-tian Lu, Hong-chao Zhang

\section{FLOW SIMULATION AND MODEL ANALYSIS OF EFFICIENCY AND PRESSURE RATIO BEHAVIOURS IN GT4086 TURBOCHARGER COMPRESSOR}

\section{S u m m a r y}

The present paper seeks to model and simulate the function of a centrifugal GT4082 compressor and evaluates the effects of losses in the impeller, volute, and diffuser. It is also examined the mass parameter effect on the efficiency drop at different speeds. The total and static pressure drops are also examined in the volute and diffuser. Based on the experiments, the efficiency drops in these parts modeled at different mass parameters and speeds discovered to be maximized in the volute and diffuser at a specific speed. A global minimum was observed in the overall pressure drop and a global maximum in the static pressure drop versus a mass parameter.

Keywords: centrifugal compressor, efficiency, pressure ratio, impeller, diffuser, volute.

Received July 21, 2019

Accepted August 24, 2020

This article is an Open Access article distributed under the terms and conditions of the Creative Commons Attribution 4.0 (CC BY 4.0) License (http://creativecommons.org/licenses/by/4.0/). 